\title{
¿Pueden los países de América Latina y el Caribe emular el modelo irlandés para atraer inversión extranjera directa?
}

\author{
Ruth Rios-Morales y David O'Donovan
}

\author{
Ruth Rios-Morales \\ Investigadora en \\ el School of Business Studies \\ e investigadora adjunta en \\ el Institute for International Integration \\ Studies, Trinity College, \\ Universidad de Dublín \\ •riosmorr@tcd.ie \\ David T. O'Donovan \\ Ex Consultor Principal en negocios \\ internacionales de la Industrial \\ Development Agency-Ireland \\ Asesorías al Banco Mundial, \\ las Naciones Unidas y la Unión Europea \\ $\bullet$ davidtodonovan@eircom.net
}

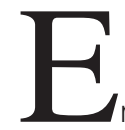

n la era de la globalización, la inversión extranjera directa (IED) es un factor indispensable para el desarrollo de la economía. Es por ello que en los últimos años una de las políticas prioritarias de muchos gobiernos, incluso de América Latina, ha sido la de crear un ambiente más favorable a la inversión. Sin embargo, solo un número muy reducido de países latinoamericanos ha sido relativamente exitoso en atraer inversiones de calidad. Irlanda, en cambio, ha obtenido resultados impresionantes mediante la creación de un entorno atrayente para la IED. Los países de América Latina harían bien en emular la experiencia irlandesa, especialmente en lo que se refiere a establecer ventajas competitivas y promover con eficiencia al país como mercado para la IED. 


\section{I}

\section{Introducción}

Sin duda, el proceso mediante el cual una nación pequeña logró equipararse a las principales economías del mundo en la era de la globalización es algo que vale la pena estudiar. Irlanda, que en el decenio de 1960 era uno de los países más pobres de Europa, es actualmente uno de los más ricos del mundo, con un ingreso per cápita de 36.360 dólares (PNUD, 2004, cuadro 1). Tras haber dependido sobre todo de la agricultura, logró construir una economía sofisticada que se asienta principalmente en la tecnología avanzada y los servicios. El sector industrial genera hoy $47 \%$ del PIB y ocupa un $28 \%$ de la fuerza de trabajo. El sector de servicios contribuye con $46 \%$ del PIB y absorbe $65 \%$ del empleo, mientras que el sector agrícola representa solo $5 \%$ del PIB y $7 \%$ de la fuerza de trabajo. ${ }^{1}$

En 2004, Irlanda fue una de las pocas economías del mundo que registraron un elevado superávit comercial, equivalente a 38.400 millones de euros (Cso, 2005). Gran parte de este resultado espectacular se ha atribuido al papel desempeñado por la IED en la economía irlandesa. Sin embargo, mucho de este éxito se debe a que la aplicación de políticas industriales se ha abordado con criterio holístico y a que se han adoptado medidas macroeconómicas coherentes, como también a un sector externo favorable que ha atraído IED de alto valor agregado.

En la misma época en que Irlanda exhibía éxitos, América Latina, considerada como la región más abierta del mundo en desarrollo, vivía una situación diferente. Tras haber sido América y el Caribe la región en desarrollo que recibió la más alta proporción de la IED mundial (14\%), en la década siguiente empezó a perder su atractivo y recibió solo $7,4 \%$ de ella. Y aunque elevó esa participación durante el período de bonanza de IED registrado en la década de 1990, nunca recuperó el nivel que había alcanzado en la de 1970. A partir de 1999, la región ha tropezado con grandes dificultades para atraer inversión extranjera. Sin embargo, las corrientes de IED en el 2004 aumentaron $40 \%$. Pese a que el mundo en desarrollo ha elevado su participación en la afluencia de IED, en 2003

\footnotetext{
1 Véase www.idaireland.com.
}

la participación de América Latina en la corriente total de IED disminuyó apreciablemente, a alrededor de $8 \%$ (cuadro 1). Estudios más recientes revelan que en 2004 la participación de la región cayó a cerca de 6\% (IBM/PLI, 2005).

La documentación disponible indica que los gobiernos de América Latina centraron la atención en prioridades macroeconómicas de corto plazo y abordaron la IED con el criterio de "mientras más, mejor". Irlanda, en cambio, aplicó políticas que incluían metas de desarrollo nacional de largo plazo, orientadas a atraer inversiones de alta calidad y, lo que es más importante, el gobierno abordó el desarrollo desde una perspectiva holística, evaluando las nuevas iniciativas de política económica e industrial según las consecuencias que ellas tendrían en el atractivo de Irlanda como lugar donde invertir.

En la era de la globalización, en América Latina prácticamente no se observan efectos positivos indirectos (spillovers) de la IED en la economía (CEPAL, 2003, p. 22; CEPAL, 2004, p. 29); en Irlanda, la economía local absorbió esos beneficios, los que desempeñaron un papel importante en el crecimiento económico.

En los últimos años, una de las prioridades de la política de muchos gobiernos, incluidos los de América Latina, ha sido la de crear un ambiente más favorable a la inversión. Se acepta ampliamente que la inversión extranjera desempeña un papel importante en la economía de un país, y últimamente se ha reconocido que contribuye a reducir la pobreza. Sin embargo, la IED por sí sola no basta para lograr el desarrollo económico ni para reducir la pobreza. Lo que hace es contribuir al crecimiento económico del país receptor cuando las políticas para atraerla forman parte de la estrategia de desarrollo económico (Willem te Velde, 2001). Irlanda ha obtenido excelentes resultados creando las condiciones necesarias para fomentar el desarrollo económico y América Latina haría bien en imitar la experiencia irlandesa cuando ello proceda.

El objetivo de este trabajo es poner de relieve algunos aspectos importantes de la experiencia irlandesa que podrían aplicarse en América Latina. Tras esta introducción, la sección II evalúa el papel que desempeña la IED en la economía. La sección III examina la evolución reciente de la inversión extranjera directa en 
CUADRO 1

Mundo: Afluencia de inversión extranjera directa, por regiones y países principales (En millones de dólares)

\begin{tabular}{|c|c|c|c|c|c|c|c|c|}
\hline Región/economía & $1970-1979$ & $\%$ & $1980-1989$ & $\%$ & 1990-1999 & $\%$ & 2000-2004 & $\%$ \\
\hline Mundo & 241244,2 & & 938874,0 & & 4010278,7 & & 4219336,0 & \\
\hline Países desarrollados & 180086,3 & 74,6 & 724613,1 & 77,2 & 2669291,8 & 66,6 & 3100554,0 & 73,5 \\
\hline Alemania & 14363,9 & 6,0 & 15139,9 & 1,6 & 124615,0 & 3,1 & 263915,0 & 6,3 \\
\hline Australia & 10382,9 & 4,3 & 37180,0 & 4,0 & 62154,1 & 1,5 & 83776,0 & 2,0 \\
\hline Bélgica y Luxemburgo & 8651,2 & 3,6 & 22451,5 & 2,4 & 227093,0 & 5,7 & 176942,0 & 4,2 \\
\hline Canadá & 32346,2 & 13,4 & 37822,9 & 4,0 & 106090,9 & 2,6 & 128603,0 & 3,0 \\
\hline Dinamarca & 1078,6 & 0,4 & 2291,1 & 0,2 & 42604,9 & 1,1 & 43845,0 & 1,0 \\
\hline España & 5782,9 & 2,4 & 33814,4 & 3,6 & 105723,5 & 2,6 & 158951,0 & 3,8 \\
\hline Estados Unidos & 32190,0 & 13,3 & 336805,0 & 35,9 & 890636,0 & 22,2 & 697492,0 & 16,5 \\
\hline Francia & 14352,2 & 5,9 & 8180,6 & 4,1 & 226983,0 & 5,7 & 209577,0 & 5,0 \\
\hline Irlanda & 1370,2 & 0,6 & 2209,5 & 0,2 & 38946,1 & 1,0 & 100419,0 & 2,4 \\
\hline Italia & 5882,2 & 2,4 & 18872,7 & 2,0 & 39497,1 & 1,0 & 76020,0 & 1,8 \\
\hline Japón & 1240,0 & 0,5 & 1806,0 & 0,2 & 26318,8 & 0,7 & 37943,0 & 0,9 \\
\hline Reino Unido & 32571,8 & 13,5 & 103919,5 & 11,1 & 324768,9 & 8,1 & 294114,0 & 7,0 \\
\hline Suecia & 766,9 & 0,3 & 7063,8 & 0,8 & 130093,7 & 3,2 & 47808,0 & 1,1 \\
\hline Suiza & 0,0 & 0,0 & 9411,1 & 1,0 & 44418,6 & 1,1 & 55430,0 & 1,3 \\
\hline Países en desarrollo & 61091,8 & 25,3 & 213561,7 & 22,7 & 1217689,9 & 30,4 & 1026116,0 & 24,3 \\
\hline América Latina y el Caribe & 32694,5 & 13,6 & 74381,1 & 7,9 & 444322,1 & 11,1 & 351580,0 & 8,3 \\
\hline Argentina & 1305,6 & 0,5 & 5844,0 & 0,6 & 68130,5 & 1,7 & 20874,0 & 0,5 \\
\hline Brasil & 12698,4 & 5,3 & 17214,2 & 1,8 & 99216,5 & 2,5 & 100136,0 & 2,4 \\
\hline Chile & 590,6 & 0,2 & 4376,1 & 0,5 & 32466,9 & 0,8 & 23598,0 & 0,6 \\
\hline México & 6015,0 & 2,5 & 23873,0 & 2,5 & 90647,5 & 2,3 & 87520,0 & 2,1 \\
\hline Venezuela (Rep. & & & & & & & & \\
\hline Bolivariana de) & $-1047,9$ & $-0,4$ & 1562,7 & 0,2 & 21426,0 & 0,5 & 13343,0 & 0,3 \\
\hline Asia y el Pacífico & 17737,5 & 7,4 & 117559,1 & 12,5 & 711497,1 & 17,7 & 595794,0 & 14,1 \\
\hline China & 0,1 & 0,0 & 16186,5 & 1,7 & 290427,0 & 7,2 & 254470,0 & 6,0 \\
\hline India & 372,6 & 0,2 & 1047,5 & 0,1 & 15165,7 & 0,4 & 18775,0 & 0,4 \\
\hline Malasia & 3261,9 & 1,4 & 9647,4 & 1,0 & 48158,0 & 1,2 & 14642,0 & 0,3 \\
\hline Singapur & 3013,0 & 1,2 & 19068,0 & 2,0 & 83989,5 & 2,1 & 61818,0 & 1,5 \\
\hline Tailandia & 798,2 & 0,3 & 5098,6 & 0,5 & 31822,4 & 0,8 & 11199,0 & 0,3 \\
\hline Taiwán, prov. china & 658,7 & 0,3 & 4717,0 & 0,5 & 14591,0 & 0,4 & 12833,0 & 0,3 \\
\hline África & 10659,8 & 4,4 & 21621,5 & 2,3 & 61870,7 & 1,5 & 78742,0 & 1,9 \\
\hline \multicolumn{9}{|l|}{ Sudeste de Europa y } \\
\hline \multicolumn{9}{|l|}{ Comunidad de Estados } \\
\hline Independientes (CEI) & $\ldots$ & $\ldots$ & 78,00 & 0,0 & 52212,0 & 1,3 & 92666,0 & 2,2 \\
\hline
\end{tabular}

Fuente: UNCTAD (2005b).

los países en desarrollo y los factores que la determinan. La sección IV evalúa las estrategias de IED en América Latina, y la sección $\mathrm{V}$ señala casos en que las políticas aplicadas en América Latina en la era de la globalización no dieron resultados. La sección VI examina el modelo irlandés para atraer IED, subrayando la importancia de la labor que realizan los organismos de promoción. La sección VII reseña las enseñanzas que pueden sacar los países latinoamericanos de la experiencia irlandesa. Por último, en la sección VIII se presentan las principales conclusiones y recomendaciones de este trabajo. 


\section{II}

\section{El papel de la inversión extranjera directa}

\section{en la economía}

En la era de la globalización, la IED es considerada uno de los elementos fundamentales para lograr el desarrollo económico. Se reconoce que puede generar empleo, aumentar las exportaciones y contribuir al desarrollo económico de largo plazo (Banco Mundial, 2005). Más recientemente, se ha sostenido que los efectos indirectos de la IED pueden ser un poderoso aliciente para estimular la inversión extranjera, ya que parece traer consigo un conjunto de conocimientos, técnicas de gestión, estrategias de comercialización y redes de distribución y producción que benefician a la economía del país receptor (Blomström, 2001). Por lo tanto, para la mayoría de los países la creación de un ambiente más propicio a la IED se ha convertido en un componente esencial del desarrollo económico.

Para hacer de la IED un instrumento de ese desarrollo no basta con lograr que un país se convierta en un mercado que atraiga las inversiones. Si se busca crear un entorno más adecuado para la IED es preciso abordar con criterio holístico la aplicación de políticas industriales (legislación relacionada con los derechos de propiedad, la reducción de las trabas burocráticas y el sistema tributario que rige para las empresas) y la adopción de medidas macroeconómicas (liberalización, desregulación, disponibilidad de infraestructura y de fuerza de trabajo calificada). Es indispensable coordinar estas políticas para evitar que ellas den lugar a efectos contrapuestos que diluyan o anulen sus beneficios. Tal coordinación debe darse al interior de las distintas ramas del gobierno nacional, entre esas ramas y también entre las distintas dependencias del gobierno local. Además, para que la IED sea un instrumento de crecimiento económico es preciso establecer metas de desarrollo económico de largo plazo, atendiendo a las prioridades nacionales. La IED solo contribuirá al crecimiento económico cuan- do se hayan creado las condiciones necesarias para el desarrollo económico y la economía interna esté en condiciones de absorber sus beneficios indirectos (Willem te Velde, 2001).

En algunos casos, el supuesto de que la IED beneficia a la economía porque contribuye a crear nuevos empleos y aumenta el crecimiento económico es más ilusorio que real. Por ejemplo, una buena parte de las corrientes de IED hacia América Latina en las últimas décadas se debió al proceso de privatización (Athukorala y Rajapatirana, 2003) que ha modernizado algunos sectores. Sin embargo, la privatización no es más que un cambio en la propiedad y no significa necesariamente un aumento de la capacidad productiva (UNCTAD, 1999). Por lo tanto, esa IED no ha contribuido automáticamente a crear empleos ni a aumentar las exportaciones.

Los efectos positivos de la IED en el crecimiento económico no son automáticos. Dependen del régimen de comercio del país receptor (Balasubramanyam, Salisu y Sapsford, 1996), de su nivel educativo y de las características de su capital humano (Borensztein, de Gregorio y Lee, 1998), del desarrollo tecnológico (de Mello, 1997), de la orientación exportadora de las inversiones recibidas (Willem te Velde, 2001) y de la estabilidad macroeconómica (Zhang, 2001). Asimismo, se ha demostrado que es errado suponer que la IED siempre generará efectos indirectos positivos para la economía del país receptor. Investigaciones empíricas han encontrado que en algunos casos los impactos indirectos sobre el país receptor pueden ser negativos (Aitken y Harrison, 1999; Saggi, 2000). Otros estudios indican que estos efectos solo se materializarán si las empresas locales están en condiciones de absorber las destrezas técnicas y la tecnología generadas por la IED (Blomström y Kokko, 2003; CEPAL, 2004, p. 29). 


\section{III}

\section{Evolución reciente y factores que determinan}

\section{la IED en los países en desarrollo}

Las tendencias y factores que determinan la inversión extranjera directa han variado significativamente en todo el mundo. Pese a que en la década de 1990 aumentó la participación de los países en desarrollo en las corrientes totales de IED, el principal destino de dicha inversión sigue siendo el mundo desarrollado (gráfico 1). En dicha década los países de América Latina perdieron parte de su atractivo como lugar para invertir y fueron reemplazados por los de Asia y el Pacífico, donde China ha sido el país favorito de los inversionistas extranjeros. Actualmente, China es el principal receptor de IED del mundo en desarrollo y recibe alrededor de $25 \%$ de la inversión extranjera total.

En el caso de Europa central y oriental los pronósticos eran favorables, ya que la bonanza del decenio de 1990 favoreció a esta región con el crecimiento acelerado de las corrientes de IED recibidas; pero a partir del 2000 estas corrientes han declinado (UNCTAD, 2004). África tropieza con dificultades similares a las de América Latina. Pese a que muchos países africanos han realizado reformas económicas y puesto en práctica políticas encaminadas a crear un ambiente más favorable a la inversión extranjera, la región africana no ha logrado atraer un volumen significativo de IED. Aunque a menudo se ha sostenido que esto se debe al ambiente hostil a la IED que existiría en los países africanos (Jenkins, 2002), el trasfondo real es que los factores que determinan la IED han cambiado y se han hecho más numerosos, y para que un mercado sea competitivo es preciso desplegar esfuerzos en muchos campos.

Actualmente, uno de los rasgos principales de la IED es que el grueso de las corrientes de inversión extranjera hacia los países en desarrollo tienden a concentrarse en un número reducido de países (Addison y Heshmati, 2003). En la economía global, el atractivo general de un país como mercado potencial de IED depende del balance de los beneficios, costos y riesgos asociados al hecho de hacer negocios en ese país. Aunque el crecimiento acelerado de la economía global ha modificado los factores que influyen en la afluencia de IED a los países en desarrollo, al evaluar un mercado para la inversión extranjera siguen siendo

GRÁFICO 1

Mundo: comportamiento de la inversión extranjera directa, 1970-2004

(En millones de dólares)

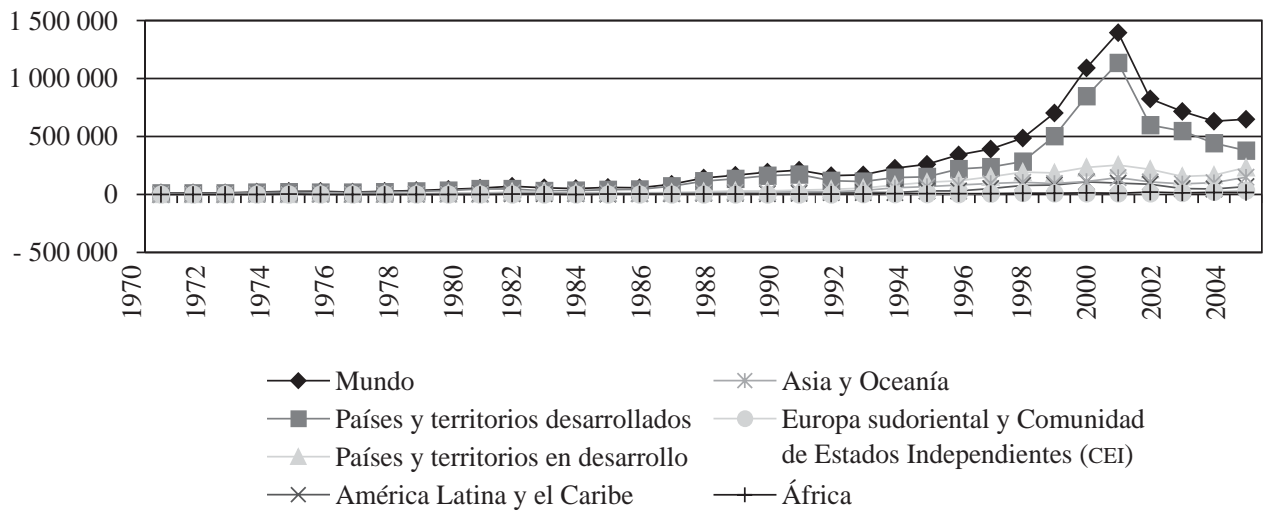

Fuente: UNCTAD (2005b). 
importantes factores de larga data, como los recursos naturales, la ubicación del país y la infraestructura (Nunnenkamp y Spatz, 2002). Con todo, ellos no bastan para crear un mercado que atraiga esa inversión.

La lista de lo que se necesita para establecer un ambiente más favorable a la IED es larga. Los estudios recientes sobre el tema destacan las características institucionales como nuevos e importantes elementos. Entre ellas cabe mencionar el grado de estabilidad política, de intervención estatal en la economía y de apertura comercial, la legislación sobre los derechos de propiedad, las trabas burocráticas y los impuestos sobre las empresas (de Mello, 1997; Rodrik, Subramanian y Trebbi, 2002). Por su parte, los últimos trabajos acerca de los incentivos para captar IED apuntan a la corrupción como un importante disuasivo (Mauro, 1995; Oman, 2000; Church, Gandal y Krause, 2002). Con todo, algunos países han logrado atraer inversión extranjera pese a ella (Kolstad y Villanger, 2004), lo que indica que cuando se sopesan los beneficios, costos y riesgos de la inversión extranjera, a ciertas características del mercado se las asocia y pondera de manera diferente.

La educación y la capacitación también son elementos nuevos y significativos en la lista de los que determinan las corrientes de IED hacia los países en desarrollo. Numerosos estudios ${ }^{2}$ han señalado que en la nueva economía global ambas son esenciales para determinar la inversión extranjera directa. Por ejemplo, un influyente informe de investigación preparado por el profesor Magnus Blomström y publicado por la Organización de Cooperación y Desarrollo Económicos (OCDE) concluye que, para crear el mercado que más pueda atraer IED, los gobiernos de los países en desarrollo deben centrarse en la educación y la capacitación (Blomström, 2001, p. 178). Al mejorar la educación y por ende el capital humano, se fomenta la inversión extranjera directa orientada a las exportaciones, lo que contribuye a mantener la estabilidad macroeconómica (Zhang, 2001).

Otros elementos importantes que en muchos países han mejorado el entorno para la inversión son los acuerdos regionales y bilaterales (Ethier, 1998). Últimamente han proliferado los acuerdos comerciales suscritos por países en desarrollo. Según el World Investment Report 2005 (UNCTAD, 2005a), actualmente existen más de 2.392 tratados de inversión bilaterales. De acuerdo con estimaciones de la Organización Mundial del Comercio (OMC), en 2007 habrá más de 300 acuerdos comerciales regionales en vigor. ${ }^{3}$ Esta clase de acuerdos influye marcadamente en el destino de la inversión extranjera. Hallward-Driemeier (2003) realizó un estudio empírico sobre la influencia que ejercen los acuerdos bilaterales en el aumento de las corrientes de IED hacia los países en desarrollo y concluyó que dichos acuerdos complementan las características institucionales adecuadas como factor de atracción, pero no las sustituyen.

\section{IV}

\section{Las estrategias de las inversiones extranjeras directas en América Latina y el Caribe}

Para evaluar los factores que en el último tiempo han atraído inversiones extranjeras directas hacia América Latina se utilizará una versión modificada del modelo de Dunning (1988). Esta versión establece cuatro categorías de inversiones, según el objetivo que persiguen sus estrategias: i) acceder a recursos naturales, ii) ampliar los mercados, iii) acrecentar la eficiencia o iv) buscar ac-

\footnotetext{
2 Borensztein, de Gregorio y Lee (1998); Noorbakhsh, Paloni y Youssef (2001); Blomström (2001); Zhang (2001); Addison y Heshmati (2003).
}

tivos tecnológicos. En los últimos años, la región ha logrado atraer IED orientada a la búsqueda de recursos naturales, a la ampliación de los mercados y al logro de más eficiencia. Esta última inversión es la que destaca en el comercio exterior de América Latina, y solo fue atraída por un número reducido de países. Al parecer, en la región no se llevan a cabo inversiones significativas centradas en la búsqueda de activos tecnológicos.

\footnotetext{
${ }^{3}$ Véase http://www.wto.org/english/tratop_e/region_e/regfac_e.htm.
} 


\section{Inversiones que buscan recursos naturales}

En los últimos 100 años, los recursos naturales han sido el principal motor de la IED en América Latina (CEPAL, 2004). Las empresas transnacionales han invertido en petróleo, en gas y en la industria minera, especialmente en el Cono Sur (cuadro 2).

Últimamente ha aumentado el interés de los inversionistas extranjeros en explotar el gas natural. Tras el descubrimiento de reservas de gas en Argentina, Bolivia, Brasil, Ecuador, Colombia y Perú en la década de 1990, las empresas internacionales de hidrocarburos han dado muestras de interés creciente por invertir en gas en el sur de la región. El inversionista más importante en el sector ha sido la compañía francesa Totalfina, que se ha dedicado principalmente a la exploración y explotación de reservas de hidrocarburos en Argentina, Bolivia, Colombia, la República Bolivariana de Venezuela y Trinidad y Tabago. La Petrobrás, empresa transnacional controlada por el Estado brasileño, está desempeñando un papel impor- tante en el desarrollo de la industria gasífera en la región. Ha invertido en Angola, Argentina, Bolivia, Ecuador, Estados Unidos, Nigeria, Perú y la República Bolivariana de Venezuela, y ocupa el $144^{\circ}$ lugar entre las 500 principales empresas del mundo (CEPAL, 2004). En el sector del turismo los receptores más importantes de IED fueron México y la Cuenca del Caribe.

Hoy la mayor parte de los recursos naturales continúa exportándose como materia prima, de manera que en las economías latinoamericanas la creación de valor agregado por este tipo de inversiones es mínima (CEPAL, 2004). Por consiguiente, no hubo efectos indirectos positivos en términos de transferencia y absorción de tecnología, integración vertical de la producción, capacitación de recursos humanos y desarrollo de empresas locales (CEPAL, 2004, p. 44). El informe sobre la inversión extranjera en América Latina y el Caribe en 2004 (CEPAL, 2005) señala que dichos efectos indirectos positivos han estado ausentes incluso en México y la Cuenca del Caribe, subregión

CUADRO 2

América Latina y el Caribe: Estrategias de inversión extranjera directa

\begin{tabular}{|c|c|c|c|}
\hline Estrategias & Búsqueda de recursos naturales & Búsqueda de mercados locales & Búsqueda de más eficiencia \\
\hline \multicolumn{4}{|l|}{ Sectores } \\
\hline \multirow[t]{2}{*}{ Bienes } & $\begin{array}{l}\text { Petróleo y gas: } \\
\text { Comunidad Andina } \\
\text { Argentina, Trinidad y Tabago }\end{array}$ & $\begin{array}{l}\text { Industria automotriz: Mercosur } \\
\text { Industria química: Brasil }\end{array}$ & $\begin{array}{l}\text { Ind. automotriz: México } \\
\text { Electrónica: México y Cuenca del } \\
\text { Caribe }\end{array}$ \\
\hline & $\begin{array}{l}\text { Minería: Comunidad Andina, } \\
\text { Chile y Argentina }\end{array}$ & $\begin{array}{l}\text { Industria alimentaria: Argentina, Brasil } \\
\text { y México } \\
\text { Bebidas: Argentina, Brasil y México } \\
\text { Tabaco: Argentina, Brasil y México }\end{array}$ & $\begin{array}{l}\text { Vestuario: México y Cuenca del } \\
\text { Caribe }\end{array}$ \\
\hline \multirow[t]{5}{*}{ Servicios } & $\begin{array}{l}\text { Turismo: México y Cuenca del } \\
\text { Caribe }\end{array}$ & $\begin{array}{l}\text { Finanzas: Argentina, Brasil, Chile, } \\
\text { Colombia, México, Perú y República } \\
\text { Bolivariana de Venezuela }\end{array}$ & $\begin{array}{l}\text { Servicios de administración: Costa } \\
\text { Rica }\end{array}$ \\
\hline & & $\begin{array}{l}\text { Telecomunicaciones: Argentina, Brasil, } \\
\text { Chile, Perú y la República Bolivariana } \\
\text { de Venezuela }\end{array}$ & \\
\hline & & $\begin{array}{l}\text { Comercio minorista: Argentina, Brasil } \\
\text { y México }\end{array}$ & \\
\hline & & $\begin{array}{l}\text { Energía eléctrica: Argentina, Brasil, } \\
\text { Chile, Colombia y Centroamérica }\end{array}$ & \\
\hline & & $\begin{array}{l}\text { Distribución de gas: Argentina, } \\
\text { Bolivia, Chile y Colombia }\end{array}$ & \\
\hline
\end{tabular}

Fuente: CEPAL (2005, cuadro 1.6). 
que sí atrajo inversiones centradas en la búsqueda de eficiencia.

\section{Inversiones que buscan ampliar mercados}

Proporcionalmente, las empresas que invierten en América Latina movidas por el interés de llegar a los mercados locales son más que las que hacen inversiones de otras categorías. Las empresas transnacionales que producen alimentos han elegido los mercados de mayor población, como Brasil, México y Argentina, mientras que el Mercado Común del Sur (Mercosur) ha atraído a la industria automotriz (cuadro 2). ${ }^{4}$ Sin embargo, en la región destacan más las empresas que buscan mercados locales en el sector de servicios, las cuales han invertido principalmente en el sistema bancario, las telecomunicaciones, la energía eléctrica y la distribución de gas.

En el período 1996-2003, las corrientes de IED dirigidas a América Latina se desplazaron hacia los servicios $(59 \%)$, mientras que la industria manufacturera recibió $28 \%$ y el sector de productos básicos, $13 \%$ (CEPAL, 2004). También variaron las fuentes principales de IED hacia América Latina y el Caribe. Aunque Estados Unidos continuó siendo el principal inversionista, pues originó alrededor de $33 \%$ del total de la IED en la región (CEPAL, 2004), la inversión europea ha aumentado marcadamente desde que tuvieron lugar las privatizaciones. Actualmente España es la segunda fuente principal de IED, con $16 \%$ del total, y en la región también hay inversionistas de los Países Bajos, Francia y el Reino Unido.

Las empresas españolas desempeñan un papel protagónico en el sector de servicios, especialmente en las telecomunicaciones y el sistema bancario. Los bancos españoles Santander Central Hispano ( $\mathrm{SCH}$ ) y

\footnotetext{
${ }^{4}$ En marzo de 1991, Argentina, Brasil, Paraguay y Uruguay suscribieron el Tratado de Asunción, que dio origen al Mercosur. Este tratado abre oportunidades para que las empresas amplíen su mercado.
}

Bilbao Vizcaya Argentaria (BBVA) poseen $52 \%$ de los activos de los 10 principales bancos transnacionales de la región (CEPAL, 2005). En el caso de las telecomunicaciones, la reciente compra de la empresa de telefonía celular BellSouth (estadounidense) por Telefónica (española) permitirá que esta última continúe liderando el sector. A su vez, en la distribución de electricidad y gas, la Endesa (española) se cuenta entre las principales empresas extranjeras que ocupan un lugar destacado en el Cono Sur, salvo Brasil.

\section{Inversiones que buscan una mayor eficiencia}

Atraer este tipo de inversiones hacia América Latina ha sido más difícil. Sólo México y la Cuenca del Caribe recibieron IED dirigida a lograr más eficiencia en la producción de bienes. En México esta clase de inversiones va a la industria automotriz, electrónica y de vestuario, y se ha visto fortalecida por el Tratado de Libre Comercio de América del Norte. En la Cuenca del Caribe, en cambio, va principalmente al sector de prendas de vestir y en alguna medida a la industria electrónica. El Tratado de Libre Comercio entre Centroamérica y Estados Unidos no modificará sustancialmente esta situación. La planta de montaje y prueba de semiconductores instalada por Intel en Costa Rica es un ejemplo de inversiones en el sector de la electrónica.

Aunque las inversiones en esta subregión impulsaron las exportaciones, tuvieron escasos efectos indirectos positivos en materia de transferencia y absorción de tecnología, integración vertical de la producción, capacitación de recursos humanos y desarrollo de la empresa privada local (CEPAL, 2004, p. 44). Costa Rica ha logrado atraer IED orientada a lograr más eficiencia en el sector de servicios, cuya exportación ha aumentado con las oficinas de apoyo administrativo (back-office) y los centros de llamados. Este pequeño país (3,5 millones de habitantes) se abrió camino gracias a su estabilidad política y económica, el alto nivel educativo de sus jóvenes y la proximidad al mercado del norte. 


\section{Políticas para atraer la inversión extranjera directa aplicadas en América Latina y el Caribe}

El hecho de que en los últimos 15 años América Latina y el Caribe haya perdido su cuota de participación en las corrientes de IED demuestra que, dada la competencia que hoy existe en el mercado, las políticas para incentivar esta clase de inversiones en la mayoría de los países de la región no fueron muy fructíferas. En medida menor, su ineficacia se debió a que abordaron la IED con un criterio inadecuado, ya que los gobiernos atendieron más a las prioridades macroeconómicas de corto plazo que al desarrollo económico de largo plazo. Cabe señalar que gran parte de la afluencia de inversión extranjera a la región se concretó a través de la adquisición de empresas existentes (Athukorala y Rajapatirana, 2003), a veces en el contexto de programas de privatización (CEPAL, 2004). Además, las inversiones en campos totalmente nuevos fueron contadas, y este es el tipo de inversión que contribuye a crear nuevas plantas, aumentar la capacidad productiva y generar más valor económico.

Mucho ha cambiado desde la época en que América Latina era la región en desarrollo preferida por los inversionistas extranjeros. En la década de 1980, algunos países comenzaron a estimular la IED mediante políticas macroeconómicas y mecanismos de promoción industrial, tales como impuestos bajos, subsidios y préstamos a los inversionistas extranjeros, y en algunos casos incluso otorgaron derechos monopólicos (Blomström, 2001). Desde entonces, para que un mercado sea atractivo como lugar de inversión se requiere algo más que disponer de recursos naturales y aplicar políticas de apertura (liberalización, privatización y desregulación de la economía), puesto que los inversionistas han podido encontrar mercados que otorgan más beneficios, con costos y riesgos menores. No hay duda alguna de que este fue el período en que América Latina empezó a perder atractivo como lugar de destino de inversiones y su participación en las corrientes de IED inició un fuerte descenso que duró hasta el 2004.

Al igual que en otras regiones del mundo, la afluencia de IED hacia América Latina se ha concen- trado principalmente en un pequeño grupo de países: Brasil, México, Argentina y Chile. En el 2003, Brasil recibió el porcentaje más alto de esas corrientes, siendo factores determinantes el tamaño del mercado interno brasileño y la posibilidad de exportar hacia otros países de la región. ${ }^{5}$ México es el segundo mayor receptor de IED en América Latina, ya que ha aumentado su competitividad gracias a los acuerdos comerciales, sobre todo el Tratado de Libre Comercio de América del Norte. Por otra parte, Argentina es el país que se ha visto más afectado por la baja de la IED en la región desde 1999 (gráfico 2); pese a que su economía ha empezado a reactivarse, le queda mucho camino por recorrer para recuperar el nivel de IED anterior a la crisis financiera (UNCTAD, 2004). En el 2003, Chile fue uno de los pocos países del mundo en que la IED aumentó. Este incremento se vio favorecido a partir del 2001 por la estabilidad económica del país y el dinamismo de su sector empresarial, basados en una sólida estructura institucional. La anterior caída de la IED en el año 2000 se había debido a la normalización que se produjo tras los flujos excepcionalmente altos de 1999.

Hemos señalado tres factores que explican por qué actualmente los países de América Latina enfrentan dificultades para captar IED. Primero, en la era de la globalización no bastan los recursos naturales para crear un ambiente que atraiga inversiones a la región. Durante más de 100 años, América Latina recibió IED principalmente gracias a sus recursos naturales (CEPAL, 2004). En el pasado, la búsqueda de recursos naturales inducía a invertir en lugares en que había materias primas y minerales. Actualmente, a los inversionistas aún les interesan los recursos naturales, pero también

\footnotetext{
${ }^{5}$ En Brasil, el principal receptor de IED fue la industria de alimentos y bebidas, seguida de los servicios de telecomunicaciones. Los inversionistas más importantes provienen de los Países Bajos (45\%) y Estados Unidos (17\%), aunque también hay inversionistas de España, México y Francia.
} 


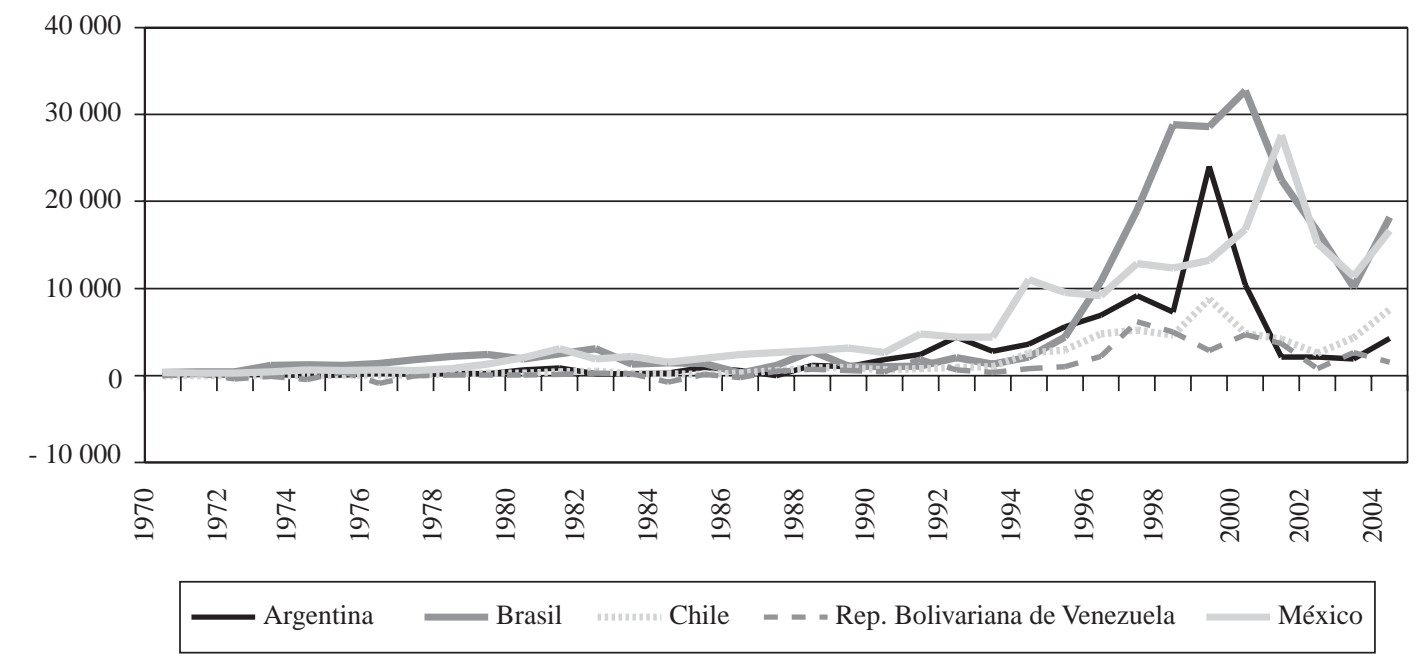

Fuente: UNCTAD (2005b).

tienen en cuenta que haya mano de obra barata, fuerza de trabajo calificada y buena infraestructura física (Kinoshita y Campos, 2004). Por otra parte, cabe destacar que, dada la inestabilidad de los precios, la IED en recursos naturales no basta para crear un ambiente favorable a las inversiones en la región. En América Latina, los recursos naturales se exportan principalmente como materia prima, lo que no genera valor agregado para la economía de los países (CEPAL, 2003).

En segundo lugar, también ha habido deficiencias importantes en la promoción de inversiones que buscan lograr una mayor eficiencia. Los inversionistas movidos por este objetivo centran su interés en la productividad de la mano de obra, el costo de los recursos, el valor de los insumos y la participación del país en mecanismos de integración regional (Dunning, 1988). En el decenio de 1990 América Latina se preocupó principalmente de recuperarse de la década anterior, descuidando aspectos importantes que hoy son decisivos para atraer IED. Mientras otros países que se disputaban la IED aplicaban políticas macroeconómicas que favorecían el crecimiento, en América Latina se utilizaban políticas monetarias y fiscales restrictivas que contribuyeron aún más a que las tasas de crecimiento de la economía y las inversiones se mantuvieran en un bajo nivel (UNCTAD, 2004, p. 620).
Los "tigres asiáticos" asignaron alta prioridad a la educación y la capacitación (Addison y Heshmati, 2003), mientras que en la mayoría de los países latinoamericanos las políticas aplicadas para incentivar la IED no contemplaron la capacitación de la fuerza de trabajo, pese a las potencialidades de capital humano existentes: por ejemplo, América Latina tiene una tasa de alfabetismo de los adultos de $88,6 \%$, cercana a la asiática de $90,3 \%$, y dentro del mundo en desarrollo exhibe el más alto índice de desarrollo humano, de 0,777, frente al de 0,74 de los países asiáticos (PNUD, 2004). Al fortalecer la disponibilidad de capital humano y de infraestructura moderna a nivel local y mejorar otros aspectos fundamentales para el crecimiento económico, los países invierten a largo plazo, puesto que los efectos indirectos de la inversión extranjera darán impulso a la economía.

En tercer lugar, los países de América Latina tampoco aplicaron políticas industriales eficaces que fueran parte de un programa de desarrollo a largo plazo. En general, frente a la IED han optado por el criterio de "mientras más, mejor", ${ }^{6}$ privilegiando la balanza de

\footnotetext{
${ }^{6}$ El criterio de "mientras más, mejor" se refiere a la práctica de atraer tanta IED como sea posible, descuidando en cierta medida su calidad.
} 
pagos o el financiamiento externo (CEPAL, 2001). No se preocuparon de establecer metas de IED ni objetivos de desarrollo nacional específicos, como aumentar la competitividad a nivel internacional, intensificar la industrialización o fomentar la transferencia de tecnología y de buenas prácticas de gestión. En los países de América Latina también ha habido evidente au- sencia de promoción y falta de vínculos entre los distintos programas (Willem te Velde, 2001, p. 28), lo cual explica que no se observen efectos indirectos positivos. Los vínculos son indispensables para canalizar la información y las destrezas de las filiales extranjeras hacia las empresas locales (Battat, Frank y Shen, 1996).

\section{VI}

\section{El modelo irlandés para atraer inversión extranjera directa}

Irlanda representa un ejemplo de éxito, con una historia de sostenido aprovechamiento de sus ventajas de ubicación y mejoramiento de su competitividad (a mediados de la década de 1990 se situaba en el cuadragésimo lugar ${ }^{7}$

En 2001-2003, Irlanda ocupó el cuarto lugar en el mundo en cuanto a desempeño como receptor de IED y su modelo de crecimiento económico ha sido aclamado como un ejemplo de desarrollo. En el decenio de 1990 la economía irlandesa exhibió los mejores resultados entre los países de la OCDE (Barry, Bradley y Hannan, 1999), con uno de los PIB per cápita más elevados del mundo, una tasa de desempleo reducida, un sistema económico y financiero estable y un alto estándar de vida. En 2005, Irlanda ocupó el primer lugar en el índice de calidad de vida que prepara la Economist Intelligence Unit. ${ }^{8}$ El éxito de la economía irlandesa en el último tiempo puede atribuirse a varias razones, pero hay consenso en que el papel de la IED fue fundamental para alcanzar esta prosperidad económica (Barry, 1999; Willem te Velde, 2001; O'Connor, 2001; Ruane y Gorg, 2000).

El resurgimiento que ha tenido Irlanda se ha debido a una combinación de acontecimientos históricos y de políticas estratégicas aplicadas en forma holística por diferentes gobiernos, con una visión de largo plazo del desarrollo económico.

\footnotetext{
${ }^{7}$ En el índice que prepara la UNCTAD sobre desempeño de los países como receptores de inversión extranjera directa (UNCTAD, 2004, p. 13). 8 Véase The Economist (2005).
}

\section{Acontecimientos históricos}

Uno de los acontecimientos históricos más importantes fue la Gran Hambruna que marcó la larga historia irlandesa de emigración involuntaria. Se ha reconocido que el masivo éxodo irlandés de la primera mitad del siglo XIX dejó a las futuras generaciones la tarea de lograr la prosperidad económica. La población de Irlanda emigró hacia países que ofrecían mejores perspectivas económicas que la tierra natal (Barry, 1999, p. 25). Hoy, la diáspora mundial irlandesa suma 70 millones de personas, la mayoría de las cuales residen en Estados Unidos (donde 44 millones de habitantes sostienen que son de origen irlandés). Por esta razón, Irlanda siempre ha mantenido una relación especial con Estados Unidos. En la actualidad, empresas tecnológicas estadounidenses han invertido miles de millones de dólares en industrias en Irlanda.

El segundo hecho histórico más importante fue el fracaso de las políticas proteccionistas que se aplicaron en 1930-1960, en el contexto del reducido mercado irlandés. En este período, la economía tuvo un desempeño muy deficiente y exhibió una tasa media anual de crecimiento de $1,67 \%$ (Ó Gráda y O'Rourke, 1996). Las políticas de sustitución de importaciones contribuyeron a crear una industria orientada exclusivamente al mercado interno, en el cual las importaciones crecieron más rápidamente que las exportaciones, generando un déficit en la balanza de pagos. Ante la prosperidad 
de otros países europeos, Irlanda se vio obligada a adoptar políticas de mercado. El tratado de libre comercio anglo-irlandés (Anglo-Irish Free Trade Agreement), suscrito en 1966, selló su compromiso con el libre comercio.

El tercer suceso importante ocurrió en 1973, fecha en que Irlanda ingresó a la entonces Comunidad Europea (CE) - hoy Unión Europea, tras la entrada en vigor del Tratado de Maastricht de 1992-. Gracias a su participación en ese esquema de integración, el país se vio muy favorecido en materia de relaciones comerciales y asistencia financiera. Desde su ingreso recibió asistencia estructural a través de distintos programas que fomentaron su cohesión económica y social. ${ }^{9}$ El respaldo financiero otorgado le permitió modernizar su infraestructura, lo que contribuyó significativamente a hacer de Irlanda un país atractivo para la IED. Desde fines del decenio de 1970 hasta principios del de 1990, las transferencias netas de la CE a Irlanda representaron entre $4 \%$ y $7 \%$ del PIB irlandés. El respaldo financiero del esquema de integración permitió a Irlanda invertir grandes sumas en infraestructura: por ejemplo, desde 1982 ha gastado 60.000 millones de dólares en la modernización de la infraestructura de telecomunicaciones. Gracias a sus éxitos económicos, en 2006 Irlanda podrá ser un contribuidor neto a la Unión Europea.

\section{Las políticas estratégicas}

El marco estratégico de políticas nacionales creado por Irlanda, que comprende políticas industriales y políticas macroeconómicas relativas a la IED, ha sido la clave del éxito de Irlanda en atraer esta clase de inversión. Sin embargo, más importante aún ha sido la utilización de la IED como método de crecimiento económico. Valiéndonos de la clasificación de las políticas industriales y macroeconómicas que hace Willem te Velde (2001), identificamos a continuación los principales elementos estratégicos que Irlanda ha utilizado.

\section{a) Políticas industriales}

i) Enfoque estratégico de largo plazo. En la década de 1960 una de las decisiones más importantes de las autoridades fue establecer objetivos de desarrollo económico de largo plazo en función de las prioridades nacionales. Dado el alto índice de desocupación, las políticas del gobierno privilegiaron la creación de

\footnotetext{
${ }^{9}$ Véase Barry, Bradley y Hannan, 1999.
}

empleos y el fomento de la inversión extranjera como elemento generador de empleo. A falta de recursos naturales, lo mejor que podía hacer Irlanda para atraer IED era educar y capacitar al mercado laboral en el uso de tecnología avanzada. Durante años los gobiernos irlandeses adoptaron este enfoque estratégico de largo plazo y aumentaron las inversiones en capacitación tecnológica, ampliaron el sistema universitario y crearon instituciones profesionales y de orientación tecnológica, así como institutos nacionales de educación superior.

ii) Creación de un marco institucional para la promoción de las inversiones. El marco institucional establecido por Irlanda con este objetivo ha sido fundamental para su éxito en captar IED. La agencia de desarrollo industrial (Industrial Development Agency), conocida como IDA-Ireland, ha fomentado la formulación y aplicación eficaces de políticas de comercialización. La instauración de Enterprise Ireland buscó estimular el surgimiento de nuevas empresas y establecer vínculos entre las empresas transnacionales y la industria local. Y en fecha más reciente se creó la Science Foundation of Ireland (SFI), que tiene por tarea promover la nueva "economía del conocimiento" irlandesa (Enterprise Ireland, 2004).

iii) Posicionamiento competitivo. La existencia de fuerza de trabajo joven con buen nivel educativo ha sido fundamental para la prosperidad económica de Irlanda. Un 37\% de sus habitantes tiene menos de 25 años, porcentaje que es el más alto de Europa (según Eurostat, la oficina de estadísticas de la Unión Europea). Las políticas del gobierno siguen apoyando a la educación, sector al cual se destina un $13 \%$ del presupuesto. Alrededor de $90 \%$ de los estudiantes secundarios finaliza su educación a los 18 años de edad; 54\% de ellos pasa a la educación superior, y cerca de $65 \%$ se concentra en el campo de la tecnología y los negocios, proporción que es la más alta en la OCDE (OCDE, 2003).

iv) Focalización en sectores de alto valor agregado. Gracias a una política de focalización sectorial, Irlanda logró crear un ambiente propicio para las inversiones en tres sectores de alto valor agregado (tecnologías de la información, industria farmacéutica y comercio internacional de servicios). En los últimos 20 años, el país se ha convertido en un terreno fértil para la tecnología y se le conoce como el centro computacional de Europa.

\section{b) Políticas macroeconómicas}

i) Solidez del desempeño y las perspectivas de la macroeconomía. La economía irlandesa ha mostrado 
ser marcadamente adaptable en la era de la globalización. La inflación se ha mantenido en un bajo nivel y actualmente se sitúa en torno al 2,02\% anual (CSO, 2005), siendo la más baja entre los países de la OCDE. En el último tiempo, el presupuesto fiscal y la balanza comercial han registrado un superávit apreciable que ha permitido aplicar una política fiscal fuertemente orientada al crecimiento (cuadro 3). Uno de los elementos importantes que han convertido al país en un lugar atractivo para la IED ha sido su política fiscal proactiva. No hay duda de que el otorgamiento de franquicias y subsidios y la fuerte inversión en promoción, junto con el régimen de impuestos bajos sobre las empresas, contribuyeron mucho al buen desempeño económico.

ii) Apertura de la economía. El fracaso de las políticas proteccionistas dio lugar a un amplio consenso nacional en torno a la orientación de la política económica e industrial. En Irlanda no ha habido diferencias de opinión al respecto. No hubo debate entre izquierda y derecha sobre la apertura de la economía, puesto que los dos partidos políticos principales son conservadores de centro derecha. Las diferencias entre ellos derivan de la guerra civil de la década de 1920 y no guardan relación con la política económica.

iii) Creación de un ambiente económico propicio. A la disponibilidad de fuerza de trabajo calificada y de infraestructura, Irlanda agregó programas de incentivos fiscales y financieros. Los incentivos financieros se otorgan en calidad de subsidios a la inversión y a la

CUADRO 3

Irlanda: Comercio exterior

(Millones de dólares)

\begin{tabular}{|c|c|c|c|}
\hline Año & Importaciones & Exportaciones & Superávit comercial \\
\hline 1988 & 12970,10 & 15623,90 & 2653,90 \\
\hline 1989 & 15597,80 & 18534,40 & 2936,60 \\
\hline 1990 & 15832,10 & 18203,90 & 2371,80 \\
\hline 1991 & 16317,20 & 19070,10 & 2752,90 \\
\hline 1992 & 16753,90 & 21260,20 & 4506,30 \\
\hline 1993 & 18899,70 & 25178,50 & 6278,80 \\
\hline 1994 & 21945,40 & 28890,90 & 6945,50 \\
\hline 1995 & 26180,90 & 35330,10 & 9149,20 \\
\hline 1996 & 28479,50 & 38608,90 & 10129,40 \\
\hline 1997 & 32863,50 & 44868,00 & 12004,50 \\
\hline 1998 & 39715,00 & 57321,80 & 17606,80 \\
\hline 1999 & 44327,10 & 66956,20 & 22629,10 \\
\hline 2000 & 55908,80 & 83888,90 & 27980,10 \\
\hline 2001 & 57384,20 & 92689,90 & 35305,70 \\
\hline 2002 & 55628,10 & 93675,20 & 38047,10 \\
\hline 2003 & 47864,60 & 82076,10 & 34211,50 \\
\hline 2004 & 50565,50 & 84160,10 & 33594,60 \\
\hline
\end{tabular}

Fuente: CSO (2005). capacitación, créditos con bajas tasas de interés, etc. Los incentivos fiscales forman parte del sistema de impuestos bajos sobre las empresas, que es reconocidamente uno de los pilares fundamentales del atractivo de Irlanda para las empresas transnacionales (Ruane y Gorg, 2000, p. 8). El sistema tributario irlandés permaneció invariable durante largo tiempo. Entre 1954 y 1980 la tasa del impuesto sobre las utilidades de las empresas manufactureras fue de $0 \%$. Desde 1980 — y hasta el 2010 para aquellas empresas que tenían derecho a ese $0 \%$ en julio de 1998- la tasa que rige es de $10 \%$ sobre las utilidades manufactureras. A las empresas nuevas (creadas a partir del 2003), se les aplica un impuesto de 12,5\% sobre los ingresos de su actividad comercial.

\section{c) Otros factores: el consenso nacional}

A partir de fines de la década de 1980, Irlanda aprobó una serie de acuerdos nacionales sobre salarios e impuestos como parte del Programa de Recuperación Nacional. La crisis económica irlandesa de mediados de esa década dio lugar a negociaciones entre el gobierno, los empleadores y los dirigentes sindicales. Las negociaciones más importantes, en las que estuvieron representados los principales empleadores e intereses laborales, condujeron a un acuerdo (Social Partnership Agreement) que firmaron las tres partes involucradas. Este acuerdo tripartito, renegociable cada tres años, contribuyó a moderar las demandas salariales y a reducir la inflación.

La base del marco de políticas estratégicas que se ha descrito fue un esfuerzo deliberado por asegurar la coordinación de las políticas en los planos nacional y local. La prueba de fuego de toda nueva iniciativa de política era evaluar si aumentaría u obstaculizaría las inversiones en Irlanda de inversionistas tanto externos como internos, criterio que fue crucial porque permitió rechazar o modificar a veces algunas políticas bien inspiradas que podían tener efectos adversos indeseados o impensados en las inversiones. Este enfoque holístico del desarrollo daba tranquilidad a los inversionistas extranjeros, porque demostraba que los sucesivos gobiernos de Irlanda asignaban importancia a sus inversiones.

\section{El marco institucional irlandés para la promo- ción de las inversiones}

Este marco merece el lugar de honor entre los exitosos esfuerzos realizados por Irlanda para atraer IED, crear vínculos entre la industria extranjera y la local y realzar 
sus ventajas competitivas. La promoción de las inversiones en Irlanda ha incluido campañas para mejorar la imagen pública, estrategias de comercialización, incentivos fiscales y financieros, asistencia a los posibles inversionistas y promoción de vínculos entre los inversionistas extranjeros y la industria nacional. Últimamente, los esfuerzos se han dirigido a establecer una nueva imagen de marca para el país como una "economía del conocimiento". Con este fin se crearon tres instituciones: la Industrial Development Agency, en 1969; Enterprise Ireland, en 1993, y la Science Foundation of Ireland, iniciada en 2003.

\section{a) Industrial Development Agency (IDA-Ireland)}

Esta agencia de desarrollo industrial fue creada para llevar a cabo actividades relacionadas con el fomento de las inversiones. Su principal objetivo fue captar inversiones externas para el sector manufacturero y los servicios internacionales, con miras a generar empleo. Desde su establecimiento, la IDA-Ireland ha desempeñado un papel fundamental en el apoyo y la gestión de la mayoría de los programas de fomento de las inversiones. Aunque a lo largo de los años la importancia de su objetivo principal no ha decaído, un aspecto esencial de su política ha sido el de maximizar los beneficios económicos y sociales de la inversión extranjera.

i) Estrategia de focalización sectorial. Un tema central en la agenda de la IDA-Ireland ha sido la elaboración de estrategias para atraer inversiones extranjeras de calidad. La primera empresa transnacional que instaló una planta en Irlanda fue la Digital Equipment Corporation y en la decisión de los inversionistas influyó decisivamente la intervención de la IDA-Ireland. En 2004 había más de 1.022 empresas transnacionales en el país, que daban empleo a 128.946 personas. Como se aprecia en el cuadro 4, esas empresas extranjeras provenían en su mayoría de Estados Unidos (478), Alemania (140) y el Reino Unido (116), pero las corrientes de IED que recibe Irlanda son de variado origen.

Aunque las empresas transnacionales participan en una amplia gama de actividades, los sectores que han captado más IED son las tecnologías de la información y de las comunicaciones, las industrias farmacéutica y de salud y los servicios financieros internacionales. De la afluencia total de IED a Europa, Irlanda ha atraído un $41 \%$ de los proyectos informáticos, $31 \%$ de los farmacéuticos y de tecnologías médicas y $34 \%$ de los servicios paneuropeos compartidos (IDA-Ireland, 2003, p. 5). La gran cantidad de fuerza de trabajo altamente calificada existente en el país se ha correspondido con las
CUADRO 4

Irlanda: La inversión extranjera, 2004

\begin{tabular}{lrr}
\hline País de origen & Número de empresas & Empleo total \\
\hline Alemania & 140 & 11 \\
Australia & 6 & 158 \\
Austria & 7 & 305 \\
Bélgica & 13 & 954 \\
Bermuda & 9 & 420 \\
Canadá & 16 & 960 \\
China & 1 & 6 \\
Dinamarca & 8 & 1814 \\
España & 3 & 14 \\
Estados Unidos & 478 & 230 \\
Finlandia & 4 & 399 \\
Francia & 41 & 226 \\
Grecia & 1 & 48 \\
Israel & 1 & 63 \\
Italia & 23 & 560 \\
Japón & 32 & 639 \\
Liechtenstein & 1 & 10 \\
Luxemburgo & 2 & 160 \\
Noruega & 1 & 20 \\
Países Bajos & 41 & 2933 \\
Reino Unido & 116 & 624 \\
República de Corea & 6 & 205 \\
Sudáfrica & 2 & 31 \\
Suecia & 14 & 230 \\
Suiza & 25 & 2645 \\
Taiwán, prov. china & 1 & 7 \\
Turquía & 2 & 54 \\
Otros no europeos & 3 & 127 \\
Total & 998 & 101 \\
\hline
\end{tabular}

Fuente: Encuesta anual de empleo (Forfás, 2005).

necesidades de IED para proyectos de tecnología avanzada. La presencia de empresas transnacionales ha contribuido de manera apreciable a mejorar las condiciones de vida. Por ejemplo, en el 2003 la remuneración anual media que pagaban las empresas transnacionales era de 37.000 euros (IDA-Ireland, 2003, p. 4).

ii) Comercialización. A través de su red de oficinas en el exterior, la IDA-Ireland da a conocer las ventajas del país para las empresas transnacionales de tecnología avanzada, poniendo de relieve la competitividad y la estabilidad de la economía, los conocimientos especializados de su fuerza de trabajo altamente calificada, el régimen tributario favorable y los incentivos financieros disponibles. La capacidad y experiencia de la IDA-Ireland en la tarea de atraer empresas transnacionales extranjeras son ampliamente reconocidas. ${ }^{10}$

${ }^{10}$ Por ejemplo, véase Loewendahl (2001). 
Como se indica en MacSharry y White (2000), ${ }^{11}$ la atención de dicha agencia se centró por primera vez en sectores como la biotecnología, los programas informáticos, la electrónica y la atención de la salud a comienzos de la década de 1980. Se individualizaron las empresas más importantes de estos sectores, se establecieron contactos con ellas y se crearon relaciones de largo plazo - hasta por 10 años con algunas de ellas, como IBM e Intel- antes de que ellas resolvieran establecer bases de exportación en Europa. En 1974-1975, compañías locales generaron dos tercios de los empleos en el sector manufacturero, correspondiendo el resto a empresas transnacionales. Sin embargo, en 1998-1999 eran estas últimas las que proporcionaban casi la mitad de los empleos manufactureros.

iii) Inversiones en actividades de promoción. A lo largo de los años, la IDA-Ireland ha realizado grandes inversiones en promoción, gracias a que ha contado con apreciables recursos presupuestarios. Se calcula que en el período 1996-2002 el costo anual medio por puesto de trabajo fue de 15.897 euros. En el año 2003, según el informe anual correspondiente de la agencia, sus gastos se elevaron a 155 millones de euros, $62 \%$ de los cuales se destinaron a subsidios a la industria, $22 \%$ a promoción y gestión y $6 \%$ a urbanización (IDA-Ireland, 2003). Por otra parte, ese mismo año el gobierno de Irlanda recaudó impuestos sobre las empresas por valor de 2.600 millones de euros solamente en el sector de IED, que a la sazón proporcionaba 18.993 empleos de jornada completa.

iv) Divulgación de información. La IDA-Ireland se ha desarrollado con rapidez desde su fundación. Actualmente tiene 280 funcionarios, incluidos 40 que cumplen funciones en 13 oficinas repartidas alrededor del mundo, que entregan información valiosa a los inversionistas y respaldan los servicios en red con el fin de minimizar los gastos burocráticos.

\section{b) Enterprise Ireland}

La Enterprise Ireland fue creada para prestar apoyo profesional a las empresas irlandesas que trabajan en el país. Esta meta se ha cumplido con éxito a través del fomento de la innovación y la productividad, el respaldo a la creación de empresas nuevas, el estímulo al desarrollo de empresas y la capacitación en la actividad comercial. Estos son los elementos clave que han permitido que las empresas irlandesas compitan exitosamente en los mercados internacionales.

\footnotetext{
${ }^{11}$ Uno de estos autores fue director ejecutivo de la IDA-Ireland.
}

i) Creación de vínculos. Desde sus inicios, la Enterprise Ireland ha cumplido una función importante y eficaz en la creación de vínculos entre las necesidades de abastecimiento de las filiales extranjeras y las características de la producción de los proveedores locales. También ha estimulado la formación de fondos de capital de riesgo que en gran medida han contribuido a transformar la industria nacional de tecnología. Ejemplo de ello son Iona Technologies y Parthus Technologies. Los servicios desarrollados por la Enterprise Ireland a lo largo de los años se entregan a través de una red de 13 oficinas locales y 34 oficinas internacionales que, en cualquier momento, están dando asistencia a unas 500 ó 600 empresas irlandesas. Parte de su programa de promoción consiste en identificar compradores internacionales a través de reuniones de ventas, misiones de trabajo dentro o fuera del país y ferias comerciales.

ii) Focalización en nuevas industrias de alto nivel. La Enterprise Ireland puso en marcha en 2002 una estrategia destinada a promover una industria nueva (Building Biotech Business Strategy). Se escogió la biotecnología por estimar que esta actividad, que se aprestaba a crecer, podría dar impulso a la economía irlandesa en los años siguientes. La idea era convertir la industria irlandesa en un centro biotecnológico. La Enterprise Ireland pretende crear una nueva generación de empresas en este rubro que ayude a que Irlanda continúe figurando en el mapa tecnológico. Se ha subrayado que para sacar adelante la industria biotecnológica es necesario que haya universidades potentes en el campo de la investigación, fuerza de trabajo calificada, y apoyo del Estado y de las empresas (Enterprise Ireland, 2004). Al parecer, la Enterprise Ireland ha concluido que la clave está en una vigorosa labor de investigación en las universidades, por lo que se ha preocupado de apoyar las investigaciones universitarias con mayores posibilidades de generar nuevo conocimiento, consideradas base fundamental de las tecnologías nuevas y de las empresas competitivas.

\section{c) Science Foundation Ireland}

Para mantener la competitividad de Irlanda en la economía mundial, en 2003 se creó la Science Foundation Ireland. Se encomendó a esta fundación la tarea de fomentar la investigación científica y la innovación industrial, con miras a promover la imagen de Irlanda como una economía del conocimiento. El tema del conocimiento, bajo el lema "Ireland, knowledge is in our nature" (Irlanda, el conocimiento está en nuestra esencia), se ha convertido en el mensaje clave para 
atraer IED. El papel de la fundación es lograr que Irlanda sea reconocida como centro de investigación de excelencia en áreas científicas de carácter estratégico para el desarrollo económico.

En opinión de quienes formulan las políticas, la Science Foundation Ireland es la entidad que asegurará que Irlanda se ponga a la vanguardia del desarrollo científico. En el período 2000-2006, la fundación entregará 646 millones de euros a investigadores académicos que trabajen especialmente en biotecnología y en tecnología de las comunicaciones. La institución está empeñada en atraer al país a científicos e ingenieros de todo el mundo para que contribuyan a desarrollar en Irlanda una economía basada en el conocimiento.

\section{VII}

\section{Aprender del modelo irlandés y seguir avanzando}

La competitividad de los países asiáticos ha amagado la posición de los países de América Latina en el mercado global, no solo porque la región no ha logrado atraer inversiones de calidad, sino también porque ha descuidado factores importantes que podrían haber usado la IED como herramienta de crecimiento. El desafío que enfrentan los países latinoamericanos es el de avanzar desde la captación de inversiones encaminadas predominantemente a obtener recursos naturales y a ampliar mercados, hacia la captación de inversiones que buscan mayor eficiencia y activos tecnológicos. Aunque no todos los elementos del modelo irlandés pueden aplicarse en América Latina, hay algunos aspectos importantes de considerar.

\section{Formulación de metas de desarrollo económi- co de largo plazo}

Para todos los países es esencial adoptar planes de desarrollo económico de largo plazo que incluyan la IED como un factor de crecimiento económico. Irlanda demoró cerca de 30 años en construir un mercado competitivo y propicio para la IED. A mediados del decenio de 1990, el país ocupaba el cuadragésimo lugar entre los receptores de IED; últimamente ha ocupado el cuarto lugar entre todos los países (UNCTAD, 2004, p. 13), y el séptimo lugar en cuanto a la afluencia de proyectos de IED en la primera mitad del 2005 (OCO Consulting, 2005).

\section{Identificación de las ventajas comparativas del país}

El modelo irlandés es notable, pues hizo que un país pequeño y con escasos recursos lograra aumentar su competitividad gracias a la eficacia de sus políticas industriales y de su promoción de la inversión extranjera directa. Irlanda ha estado invirtiendo fuertemente en infraestructura humana (Durkan, FitzGerald y Harmon, 1999). Su ventaja competitiva reside en una población joven con una buena educación. La disponibilidad de fuerza de trabajo de alto nivel educativo y capacitada en el campo de la tecnología avanzada contribuye no solo a atraer IED, sino también a que las inversiones sean de calidad (Lall, 1997).

La competitividad de América Latina, en cambio, se ha construido en torno a su ventaja comparativa derivada de la disponibilidad de recursos naturales y de mano de obra barata; pero esta mano de obra está menos especializada y capacitada que la de sus competidores. En China, Malasia, Singapur y la provincia china de Taiwán, por ejemplo, el nivel educativo y la capacitación de su fuerza de trabajo influyeron mucho en la llegada de IED (Addison y Heshmati, 2003). América Latina deberá invertir en capital humano si desea reemplazar las inversiones centradas en la búsqueda de recursos naturales por otras que persigan una mayor eficiencia. Contar con un contingente de mano de obra calificada no solo es un factor determinante de la IED, sino también una condición importante para poder absorber los beneficios indirectos de esta inversión (Willem te Velde, 2001).

Según Porter (1998, p. 7), las ventajas competitivas duraderas en una economía global dependen cada vez más de elementos locales -tales como el conocimiento, las relaciones y la motivación-que sus competidores distantes no pueden equiparar.

La ubicación de América Latina debería acrecentar su competitividad relativa. Si bien es cierto que con la globalización las distancias ya no son tan importantes, 
la ubicación de un país sigue siendo muy importante en una era de competencia mundial (Porter, 2000).

\section{Promoción eficaz de las ventajas comparativas}

En Irlanda no habría bastado con las ventajas comparativas para captar IED de calidad. La promoción efectuada por la IDA-Ireland difundió la imagen del país como un mercado atractivo y hoy día el modelo de promoción que aplica esta agencia encabeza la lista de modelos eficaces utilizados por las instituciones de promoción de inversiones (Morisset y AndrewsJohnson, 2005). En los últimos años, parte importante de la estrategia de desarrollo de los gobiernos -incluidos los de América Latina- ha sido la creación de una entidad de fomento de las inversiones (Morisset, 2003), pero pocas de tales entidades han obtenido buenos resultados.

Los siguientes son algunos elementos importantes del modelo de entidad de promoción de inversiones de Irlanda que podrían aplicarse en América Latina:

i) Ofrecer un sistema de ventanilla única (one-stop shop) para atender a los inversionistas es una de las principales recomendaciones para esta clase de entidades. Consecuente con tal enfoque, la IDA-Ireland proporciona información de calidad y redes de apoyo que efectivamente permiten que los inversionistas extranjeros ahorren tiempo y dinero (Ruane y Gorg, 2000, p. 6). Los funcionarios de la IDA-Ireland se preocupan de conocer a quienes tienen poder de decisión en otras dependencias del gobierno y a las autoridades locales. Gracias a esta red de contactos pueden ayudar a los inversionistas a realizar los trámites necesarios para obtener las licencias y autorizaciones que exige la legislación irlandesa.

ii) La creación de una entidad gubernamental ajena a la administración pública y la adopción de un sistema de ventanilla única ha sido clave para el éxito del proceso de promoción. El hecho de que la entidad promotora funcione con independencia, aunque pertenezca al gobierno y deba rendirle cuentas, la hace más flexible y aumenta su credibilidad entre los inversionistas (Loewendahl, 2001, p. 8).

iii) La agencia irlandesa de fomento de las inversiones es muy dinámica. A través de su red de oficinas en el exterior, la IDA-Ireland ha difundido la imagen del país como un lugar atractivo para empresas de tecnología avanzada, poniendo de relieve la competitividad y estabilidad de su economía, el sistema tributario favorable, el acceso libre de impuestos a los mercados de la Unión Europea y los incentivos financieros disponibles.
Las actividades de promoción de inversiones realizadas por la IDA-Ireland incluyen llamados telefónicos, presentaciones y el suministro de estudios a las empresas electrónicas y farmacéuticas de Estados Unidos, Europa y Japón (Willem te Velde, 2001, p. 37).

iv) La IDA-Ireland también ha recibido importante respaldo del gobierno para dar a conocer el país como un mercado propicio para la IED. Según las conclusiones de estudios empíricos, la eficacia de una entidad de fomento está directamente relacionada con el gasto en promoción. La agencia ha dado apoyo financiero en forma de donaciones, subsidios y capacitación. De hacerse lo mismo en América Latina, convendría velar por que se evite la corrupción (Loewendahl, 2001, p. 17).

v) La puesta en marcha de un Programa Nacional para la Creación de Vínculos Interempresariales contribuyó a perfeccionar la capacidad promocional de la agencia y ha permitido establecer relaciones eficaces entre la industria nacional y la extranjera. La IDAIreland ha cumplido una función importante en la promoción de las políticas, mientras que la Enterprise Ireland ha estimulado y fomentado la industria nacional y la inversión extranjera. Otro factor que ha influido en el logro de beneficios indirectos y por lo tanto en el crecimiento económico, son los vínculos creados entre las empresas transnacionales y la industria local. En América Latina, una de las maneras más eficaces de generar efectos indirectos positivos sería establecer tales vínculos.

vi) Para promover eficazmente sus ventajas competitivas, Irlanda ha debido centrarse en sectores específicos y mirar hacia el futuro. La última medida de la política industrial irlandesa orientada a atraer IED fue crear la Science Foundation Ireland. Y la estrategia más reciente de la política dirigida a potenciar la competitividad del mercado irlandés fue dar a la fuerza de trabajo capacitación universitaria en biotecnología e informática.

\section{La creación de un ambiente económico atractivo}

Para tener éxito en atraer IED es importante una promoción eficaz. Sin embargo, cuando en el país no existe un ambiente propicio para las inversiones, esa promoción puede ser contraproducente (Morisset, 2003, p. 18). En América Latina, la liberalización del comercio, las privatizaciones y la desregulación aplicadas desde la década de 1980 no han sido suficientes. Es un hecho que para crear un ambiente económico 
estable y atractivo para la IED se requieren mayores estímulos. Entre los elementos que contribuyeron a crear un ambiente propicio para la IED en Irlanda, cabe mencionar los siguientes:

i) La estabilidad económica, las políticas macroeconómicas claras y la adopción de un sistema financiero avanzado. ii) La baja tasa del impuesto sobre las empresas, que es reconocidamente uno de los incentivos más importantes con que cuenta el país para atraer inversiones extranjeras.

iii) El acceso a los mercados de otros países.

iv) El entorno empresarial.

v) La calidad de vida.

\section{VIII}

\section{Conclusiones y recomendaciones}

En muchos países, atraer inversión extranjera se ha convertido en un nuevo método para lograr mayor crecimiento económico y reducir la pobreza. Sin embargo, atraer IED sin que existan las condiciones necesarias para alcanzar el desarrollo económico es un esfuerzo inútil. Si bien es cierto que para crear un mercado competitivo hay que desplegar esfuerzos en muchos campos, para que la IED sea un instrumento de crecimiento económico es preciso abordarla con políticas holísticas, en el marco de un plan nacional de desarrollo económico que contemple metas de largo plazo. En América Latina, el supuesto de que la IED contribuirá positivamente a la economía y generará beneficios indirectos para la industria interna ha sido más ilusorio que real. La experiencia de Irlanda revela la importancia de aplicar políticas industriales y macroeconómicas eficaces y de crear un sistema de promoción técnicamente avanzado con el fin de atraer IED que sea útil para el desarrollo económico nacional.

Gran parte de la IED que han recibido los países de América Latina en los últimos años ha adoptado la forma de adquisiciones de empresas existentes, a veces en el contexto de programas de privatización. Para crear plantas nuevas y aumentar la capacidad productiva, así como incrementar el valor económico nacional, el próximo objetivo deben ser las inversiones en proyectos totalmente nuevos. Por lo general se estima que este tipo de inversiones es el que influye más directamente en el desarrollo nacional. Tal como Irlanda centró su atención en las empresas estadounidenses en razón de lazos históricos, culturales y lingüísticos, América Latina debería aproximarse a los países europeos con los cuales comparte un legado común. En el mercado de IED ha aumentado la presencia de inversionistas europeos, y España es hoy el principal inversionista en la región. América Latina también debería tener en la mente a los países asiáticos que están iniciando o acrecentando sus inversiones internacionales (China y la República de Corea, respectivamente).

En vista de lo eficaz que ha demostrado ser la existencia en Irlanda de un marco estratégico destinado a promover la afluencia de IED de calidad, América Latina haría bien en dedicar vigorosos esfuerzos a diseñar un sistema de promoción de las inversiones.

Asimismo, las entidades de promoción de las inversiones deberían coordinar y establecer vínculos entre la IED y la industria local. La falta de esos vínculos ha sido una de las principales razones por las cuales América Latina no ha podido aprovechar los beneficios indirectos de la IED. También es importante invertir más en educación y capacitación, puesto que los factores que tradicionalmente determinaban la afluencia de IED han perdido gravitación, y actualmente lo fundamental parece ser invertir en capital humano. Si América Latina compite por la inversión extranjera sobre la sola base de sus recursos naturales y el tamaño de los mercados locales, se debilitará aún más su posición en el mercado internacional de inversión extranjera directa.

(Traducido del inglés) 
Addison, T. y A. Heshmati (2003): The New Global Determinants of FDI Flows to Developing Countries, WIDER Discussion Papers, N ${ }^{\circ} 2003 / 45$, Nueva York, Universidad de las Naciones Unidas.

Aitken, B. y A. Harrison (1999): Do domestic firms benefit from direct foreign investment?, American Economic Review, vol. 89, $\mathrm{N}^{\mathrm{o}}$ 3, Nashville, Tennessee, American Economic Association.

Athukorala, P. y S. Rajapatirana (2003): Capital inflows and the real exchange rate: a comparative study of Asia and Latin America, The World Economy, vol. 26, N ${ }^{\circ}$ 4, Oxford, Reino Unido, Blackwell Publishing.

Balasubramanyam, V., M. Salisu y D. Sapsford (1996): Foreign direct investment in EP and IS countries, The Economic Journal, vol. 106, № 434, Oxford, Reino Unido, Blackwell Publishing.

Banco Mundial (2005): Informe sobre el desarrollo mundial 2005: un mejor clima de inversiones en beneficio de todos, Washington, D.C.

Barry, F. (comp.) (1999): Understanding Ireland's Economic Growth, Londres, Macmillan Press.

Barry, F., J. Bradley y A. Hannan (1999): The European dimension: the single market and structural funds, en F. Barry (comp.), Understanding Ireland's Economic Growth, Londres, Macmillan Press.

Battat, R., I. Frank y X. Shen (1996): Suppliers to Multinationals: Linkage Programs to Strengthen Local Companies in Developing Countries, Foreign Investment Advisory Service Occasional Paper, $\mathrm{N}^{\mathrm{o}}$ 6, Washington, D.C., Banco Mundial.

Borensztein, E., J. de Gregorio y J.W. Lee (1998): How does foreign direct investment affect economic growth?, Journal of International Economics, vol. 45, $\mathrm{N}^{\circ} 1$, Amsterdam, Elsevier.

Blomström, M. (2001): The Economics of International Investment Incentives, París, Organización de Cooperación y Desarrollo Económicos (OCDE).

Blomström, M. y A. Kokko (2003): The Economics of Foreign Direct Investment Incentives, NBER Working Paper, № 9489 , Cambridge, Massachusetts, National Bureau of Economic Research.

CEPAL (Comisión Económica para América Latina y el Caribe) (2001): La inversión extranjera en América Latina y el Caribe. Informe 2001, LC/G.2125-P, Santiago de Chile. Publicación de las Naciones Unidas, $\mathrm{N}^{\mathrm{o}}$ de venta: S.01.II.G.12.

(2003): La inversión extranjera en América Latina y el Caribe. Informe 2002, LC/G.2198-P, Santiago de Chile. Publicación de las Naciones Unidas, $\mathrm{N}^{\circ}$ de venta: S.03.II.G.11. (2004): La inversión extranjera en América Latina y el Caribe, 2003, LC/G.2226-P, Santiago de Chile. Publicación de las Naciones Unidas, $\mathrm{N}^{\mathrm{o}}$ de venta: S.04.II.G.54.

(2005): La inversión extranjera en América Latina y el Caribe, 2004, LC/G.2269-P, Santiago de Chile.

CSO (Central Statistics Office Ireland) (2005): External Sector, www.cso.ie/releasespublications, junio.

Church, J., N. Gandal y D. Krause (2002): Indirect Network Effects and Adoption Externalities, CEPR Discussion Papers, $\mathrm{N}^{\circ} 3738$, Londres, Centro de investigación sobre políticas económicas (CEPR).

De Mello (1997): Foreign direct investment in developing countries and growth: a selective survey, Journal of Development Studies, vol. 34, $\mathrm{N}^{\circ}$ 1, Londres, Routledge, octubre.

Dunning, J. (1988): The eclectic paradigm of international production: a restatement and some possible extensions, Journal of International Business Studies, vol. 19, $\mathrm{N}^{\circ} 1$, Houndsmills, Palgrave Macmillan Journals.

Durkan, J., D. FitzGerald y C. Harmon (1999): Education and growth in the Irish economy, en F. Barry (comp.), Understanding Ireland's Economic Growth, Londres, Macmillan Press.
Enterprise Ireland (2004): Annual Report, Dublín, junio. (2005): Annual Report, Dublín, junio.

Ethier, W.J. (1998): The new regionalism, The Economic Journal, vol. 108, No 449, Oxford, Reino Unido, Blackwell Publishing.

Forfás (2005): Annual Employment Survey 2004, Dublín.

Hallward-Driemeier, M. (2003): Do Bilateral Investment Treaties Attract Foreign Direct Investment? Only a Bit and They Could Bite, Policy Research Working Paper Series, $\mathrm{N}^{\circ} 3121$, Washington, D.C., Banco Mundial.

IBM-PLI (IBM/ Plant Location International) (2005): Global Investment Location Database (GILD)

IDA-Ireland (Industrial Development Agency-Ireland) (2002): Annиal Report 2002, diciembre.

(2003): Annual Report 2003, Dublín, diciembre, (2004): Annual Report 2004, Dublín, diciembre,

Jenkins, R. (2002): The labour market effects of globalization in South Africa, documento presentado en el TIPS workshop on Globalization, Production and Poverty, Johannesburgo.

Kinoshita, Y. y N. Campos (2004): Estimating the Determinants of Foreign Direct Investment Inflows: How important are Sampling and Omitted Variable Biases?, BOFIT Discussion Papers, N ${ }^{\circ}$ 10/2004, Helsinki, Bank of Finland Institute for Economies in Transition (BOFIT).

Kolstad, I. y E. Villanger (2004): How Does Social Development Affect FDI and Domestic Investment?, Working Paper, $\mathrm{N}^{\circ}$ 22080, Bergen, Chr. Michelsen Institute (CMI).

Lall, S. (1997): East Asia, en J. Dunning (comp.), Governments, Globalization and International Business, Oxford, Oxford University Press.

Loewendahl, H. (2001): A framework for FDI promotion, Transnational Corporations, vol. 10, $\mathrm{N}^{\mathrm{o}}$ 1, UNCTAD/ITE/IIT/ 27, Nueva York, Conferencia de las Naciones Unidas sobre Comercio y Desarrollo (UNCTAD), abril.

MacSharry, R. y P. White (2000): The Making of the Celtic Tiger: the Inside Story of Ireland's Boom Economy, Cork, Mercier Press.

Mauro, P. (1995): Corruption and growth, Quarterly Journal of Economics, vol. 110, $\mathrm{N}^{\circ} 3$, Cambridge, Massachusetts, The MIT Press.

Morisset, J. (2003): Does a Country Need a Promotion Agency to Attract Foreign Direct Investment? A Small Analytical Model Applied to 58 Countries, World Bank Policy Research Papers, $\mathrm{N}^{\circ}$ 3028, Washington, D.C., Banco Mundial, abril.

Morisset, J. y K. Andrews-Johnson (2005): The Effectiveness of Promotion Agencies at Attracting FDI, Foreign Investment Advisory Service Occasional Paper, $\mathrm{N}^{\circ} 16$, Washington, D.C., Banco Mundial.

Noorbakhsh, F., A. Paloni y A. Youssef (2001): Human capital and FDI inflows to developing countries: new empirical evidence, World Development, vol. 29, № 9, Amsterdam, Elsevier, septiembre.

Nunnenkamp, P. y J. Spatz (2002): Determinants of FDI in developing countries: has globalization changed the rules of the game?, Transnational Corporations, vol. 11, $\mathrm{N}^{\mathrm{o}} 2$, UNCTAD/ITE/IIT/31, Nueva York, Conferencia de las Naciones Unidas sobre Comercio y Desarrollo (UNCTAD), agosto.

O'Connor, P. (2001): Foreign Direct Investment and Indigenous Industry in Ireland: Review of Evidence, ESRC Working Papers, No 22/01, Sussex, Universidad de Sussex.

Ó Gráda, C. y K. O'Rourke (1996): Living Standards and Growth, Working Paper WP00/14, Departamento de Economía, Dublín, University College Dublin.

oCDE (Organización de Cooperación y Desarrollo Económicos) (2003): education at a glance: OECD Indicators 2003, París. 
Oco Consulting (2005): The eye of the tiger: Ireland winning overseas investment, octubre, en www.locomonitor.com.

Oman, C. (2000): Policy Competition for Foreign Direct Investment: a Study of Competition among Governments to Attract FDI, París, Organización de Cooperación y Desarrollo Económicos (OCDE), marzo.

PNUD (Programa de las Naciones Unidas para el Desarrollo) (2004): Informe sobre desarrollo humano 2004: la libertad cultural en el mundo diverso de hoy, Nueva York, julio.

Porter, M. (1998): Clusters and the new economics of competition, Harvard Business Review, vol. 36, $\mathrm{N}^{\circ}$ 6, Boston, Harvard Business School.

(2000): Location, competition, and economic development: local clusters in a global economy, Economic Development Quarterly, vol. 14, $\mathrm{N}^{\mathrm{o}}$ 1, Thousand Oaks, California, Sage Publications.

Rodrik, D., A. Subramanian y F. Trebbi (2002): Institutions Rule: Institution, Integration and Geography, Harvard University Working Papers, disponible en http://ksghome.harvard.edu/ $\sim$ drodrik/papers.html.

Ruane, F. y H. Gorg (2000): European integration and peripherality: lessons from the Irish experience, The World Economy, vol. 23 , $\mathrm{N}^{\mathrm{o}} 3$, Oxford, Reino Unido, Blackwell Publishing, marzo.

Saggi, K. (2000): Trade, Foreign Direct Investment and International Technology Transfer: A Survey, Policy Research Working Paper, $N^{\circ} 2349$, Washington, D.C., Banco Mundial.

The Economist (2005): The world in 2005, disponible en http:// www.economist.com.
UNCTAD (Conferencia de las Naciones Unidas sobre Comercio y Desarrollo) (1999): World Investment Report 1999: Foreign Direct Investment and the Challenge of Development, UNCTAD/ WIR/1999, Nueva York, Naciones Unidas. Publicación de las Naciones Unidas, $\mathrm{N}^{\mathrm{o}}$ de venta: E.99.II.D.3.

(2003): World Investment Report 2003: FDI policies for development: national and international perspectives, UNCTAD/ WIR/2003, Nueva York, Naciones Unidas. Publicación de las Naciones Unidas, $\mathrm{N}^{\mathrm{o}}$ de venta: E.03.II.D.8.

(2004): World Investment Report 2004: The Shift Towards Services, UNCTAD/WIR/2004, Nueva York, Naciones Unidas. Publicación de las Naciones Unidas, $\mathrm{N}^{\circ}$ de venta: E.04.II.D.33.

(2005a): World Investment Report 2005: Transnational corporations and internationalization of $R \& D$, Nueva York, Naciones Unidas. Publicación de las Naciones Unidas, $\mathrm{N}^{\mathrm{o}}$ de venta: E.05.II.D.10.

(2005b): Foreign Direct Investment Statistics 2005, en http:// www.unctad.org/Templates/Page.asp? intItemID $=1923$ \&lang $=1$.

Willem te Velde, D. (2001): Policies Towards Foreign Direct Investment in Developing Countries: Emerging Best Practices and Outstanding Issues, Londres, Overseas Development Institute, marzo.

Zhang, K.H. (2001): Does foreign direct investment promote economic growth? Evidence from East Asia and Latin America, Contemporary Economic Policy, vol. 19, No 2. Oxford, Oxford University Press, abril. 